\title{
EL DISCURSO DE LA EXTRAÑEZA EN LA POESÍA MAPUCHE HUILLICHE ${ }^{\mathbf{1}}$
}

The Speech Discours of Strangeness in Mapuche Huilliche Poetry

\author{
Pilar Álvarez-Santullano B.* \\ Eduardo Barraza J. *
}

\section{Resumen}

Los discursos son construcciones sociales que acarrean, distribuyen, empoderan y transforman saberes y conocimientos. En esta circulación social, los discursos se vacían en distintos géneros, sean estos referenciales o literarios. Nos interesa en este artículo reflexionar sobre uno de éstos discursos que hemos denominado el discurso de la extrañeza - a partir de "De Chilensibus", un poema del libro Arco de interrogaciones de Bernardo Colipán - cuya emergencia se sitúa en textos de cronistas y se enhebra discontinuamente para aparecer, actualmente, retomado en la poesía huilliche, ahora como discurso apropiado, traducido y puesto en evidencia en la inestabilidad de su armazón lógica y en el juego de historicidades encontradas.

Palabras clave: Literatura chilena, poesía huilliche.

\section{Abstract}

Speech are a Social construction which brings about, distribute, empower and transforms knowledge. In this social circulation, discourse is poured into different genres, be they referential or literary. We are interested in a reflection over one of these types of discourse which we have called the speech of strangeness - emanating from "De Chilensibus, a poem from the book Arco de interrogaciones (by Bernardo Colipán) — whose emergence is situated in the chronicler's texts and is discontinuously entertwined to appear, in reality, refloated in huilliche poetry, now as an appropriated discourse, translated and placed in evidence in the inestability of its logical structure and in the game of confronted historicities.

Key words: Chilean literature, huilliche poetry.

\section{INTRODUCCIÓN}

La poesía mapuche "habla de espacios simbólicos o de discursos, y también de pueblos, territorios, y fronteras nacionales" (Mora Curriao, 2009:179). Es una poesía que se alza al modo de una "hebra poética con la cual zurcir la tierra legada con muchas heridas" (Huinao, 2009:126). Según Maribel Mora, se trata de "una compleja y tensionada escritura que se visibiliza sobre un fondo de conflictos arrastrados desde hace

\footnotetext{
${ }^{1}$ Resultado del Proyecto Fondecyt No 1085317 : "El discurso de la conquista: una serie textual autónoma de la literatura chilena".
} 
siglos, que aspira a contribuir de alguna manera a la recuperación y mantención de las costumbres y la cultura propia, revalorizándola a través de una escritura" (2009:179).

A diferencia de quienes indagan en la historia y la conceptualizan, la poesía mapuche huilliche de Colipán define la historia como "un espejo roto" o como "una moneda de dos caras". Se trata de una discursividad que bien puede sostener que resulta un "difícil oficio leer a Encina" —el historiador chileno- cuando habla de ellos, los conquistados, aunque no llega al extremo de apelar a que Lautaro sea borrado "de los libros y cuadernos escolares", como convoca Nelson Torres en De Indias (1994:36).

Observamos que la denominada etnoliteratura chilena — más bien literatura mapuche-huilliche, escrita más en castellano que en mapudungun - presenta una emergencia de la memoria que, entre otros tópicos, re-visita la historiografía de la conquista, y la sitúa discursivamente en el plano de una re-escritura, de una transhistoria, o de una "áspera contra-crónica", que reproduce un gesto similar a aquel mediante el cual "la indiada le perdió el respeto a los caballeros", y pudo hacerle frente con nuevos argumentos o "silogismos" (Riedemann, 1995:17) los que, en su conjunto, diseñan un gran "arco de interrogaciones", como en el libro homónimo de B. Colipán (2005), de modo que, a su amparo, se debatan cuestiones de la historia y del mito de la conquista de Chile, y de la cosmovisión identitaria y cultural de un pueblo mapuche enfrentado hoy y ayer, a una mutua extrañeza con el otro, el extranjero (huinca), ya sea español, o más tarde, el criollo.

Esta extrañeza por el otro resulta identificable en un discurso, cuya emergencia se sitúa en textos de cronistas y se enhebra discontinuamente para aparecer, actualmente, retomado en la poesía huilliche, ahora como discurso apropiado, traducido y puesto en evidencia en la inestabilidad de su armazón lógica y en el juego de historicidades encontradas. Por lo mismo, esta poesía establece relaciones contratextuales con los discursos canónicos (historiográficos y literarios), al modo de una resistencia y afirmación cultural que rescata la identidad negada o adulterada - desde el tradicional discurso de la conquista que, situado en la traza de la escritura hegemónica —al modo de Encina, por ejemplo- ha hecho referencia a su cultura, su ideología y su historia. ${ }^{2}$

\section{SOBRE LA POESÍA MAPUCHE}

A la fecha, la poesía mapuche se ha ido consolidando en el espacio de la literatura chilena por su calidad estética, adquiriendo un progresivo estatus epistemológico para la propia cultura, particularmente, cuando la reflexión poética

\footnotetext{
${ }^{2}$ Esta contratextualidad puede observarse también, por ejemplo, en Jaime Huenún, quien —entre otros aspectos - examina el estado actual de la cultura mapuche y, particularmente, el hecho de la pérdida y la consiguiente recuperación de la naturaleza incantatoria de sus espacios y de sus espíritus tutelares como Huenteao. Por esta vía, establece los nexos entre el discurso de la conquista y los protocolos (híbridos) de los "parlamentos". Cfr. Pilar Alvarez-Santullano Busch y Eduardo Barraza. "Escrituras de "encanto" y parlamento en la poesía huilliche", en Alpha № 29 (Diciembre 2009:9-22).
} 
aborda temas asociados a las pasadas y actuales relaciones interétnicas e interculturales, que históricamente este pueblo ha debido mantener con la sociedad chilena-occidental (García, 2005). Esta dirección del actual discurso poético mapuche nos pone frente a algunas de las interrogantes fundamentales que se hacen hoy las sociedades multiculturales — como la nuestra - cuando revisan el significado que han tenido las relaciones entre "la metrópoli colonizadora" y "los otros", los del Nuevo Mundo, las que terminan siendo descritas como "relaciones de resistencia cultural" (Said, 2002), como "revisiones anticolonialistas" que actualmente los pueblos "subordinados" realizan sobre el devenir de su historia, y sobre las condiciones de imposición a las que fueron sometidos. Se invierte, así, el relato tradicionalmente legitimado sobre la penetración histórica. Se les representa a las metrópolis colonialistas para verse a sí mismas como propiciadoras de culturas de represión y de segregación, como sociedades que se satisfacen en el establecimiento de una relación asimétrica con "el otro", y en la impronta de una historia de violentación hegemónica que obliga a la reflexión ética sobre la índole del contacto cultural generado entre colonizadores y colonizados (Césaire, 1993:308).

Según reseña Nagy-Zekmi —derivada del llamado "nuevo historicismo", que niega la existencia de la objetividad, y enfatiza la importancia de la representación en la formación de la conciencia humana - la contrahistoria resulta ser de naturaleza interdisciplinaria y multidiscursiva. (1996:61). La voz de la contrahistoria es, preferentemente, la de una experiencia individual que se hace pública y pro-crea un espacio positivo y creativo del que se posesiona un subalterno, en calidad de "intelectual orgánico" de esa minoría (Nagy-Zekmi, 1996:63), como resultan ser los escritores mapuche-huilliche.

Del mismo modo, cada vez que se hurga en el "palimpsesto" (Huirimilla, 2005) del discurso de la conquista, que subyace en la activa memoria del conquistado, surgen las páginas y los capítulos no escritos — pero vividos — de una etnia relegada a la subalternidad, pero que no se conforma con ella. Como advierte Nagy-Zekmi, "los esfuerzos por incluir los discursos hasta ahora considerados marginales en los cánones de la literatura son numerosos" (69). ${ }^{3}$

\footnotetext{
${ }^{3}$ Particular interés — para efectos de la traslación de los discursos marginales más hacia el centro de habla del dominador - reviste la categoría de "discurso etnocultural", presente en textos escritos por chilenos y mapuches, principalmente en la IX y X $\mathrm{X}^{\mathrm{a}}$ Región, al sur de la histórica "zona de la frontera". La poética etnocultural está destinada a poner de manifiesto la índole plural y heterogénea que caracteriza la conformación intercultural de la sociedad chilena, cuyos indicadores son — entre otros - el doble código lingüístico, la oralidad, y el prestigio de la memoria y del mito frente a la historia. Según Iván Carrasco, la textualidad etnocultural pretende "formar una conciencia abierta a la interacción sociocultural, que tienda a la disolución de las dicotomías conformadas en la escritura española de la conquista y de la colonia, que se han convertido en estereotipos de una cultura nacional" (1991:113). Una cultura nacional no interesada - hasta hace muy poco - en incorporar a la institucionalidad literaria una escritura conforme "a los cánones ancestrales de la vida indígena", o "conforme a patrones propios de comportamiento", relativos al modo de
} 
Según Foerster, en la poesía actual huilliche, "releer y refundar el pasado exige la búsqueda de un "nuevo discurso", nuevas estrategias discursivas (de nuevas metáforas, alegorías, etc.) que necesariamente entran en conflicto con el "orden del discurso" sobre lo mapuche huilliche" (2005:274). Foerster reconoce tres procedimientos que permitirían este nuevo discurso, entre estos, el "valerse del lenguaje-memoria del otro, para re-vestirse con él, para estar de un modo distinto a él", que justamente Foerster identifica en "De Chilensibus" y que señalamos como palimpsesto, es decir, como señalan Carrasco y Mora (2006) citando a Genette, como "texto que muestra ecos de un texto anterior, de modo que toda escritura es siempre el eco de otras voces". 4

De este modo, al amparo del Arco de las interrogaciones (2005), de Bernardo Colipán, el pueblo huilliche desde su situacionalidad subalterna repasa voces de otros a la vez que formula libremente una serie de preguntas básicas que no han sido enunciadas, ni oídas, ni respondidas por el Otro ("Arco del vacío", "Arco de la negación", "Arco del silencio", "Arco del amor y su figura recortada", "Arco de mis abrazos", "Arco de mis apariciones", "Arco de la memoria y la transparencia", "Arco de la historia y sus pliegues", "Arco del retorno"); interrogantes dispuestas como entrada a un modo de vivenciar el ethos cultural mapuche-huilliche (Contreras, 2005).

\section{TEXTOS Y CONTRATEXTOS DE LA POESÍA HUILLICHE}

Conforme a lo reseñado, analizaremos "De Chilensibus". Dicho texto está compuesto por tres secuencias, siendo éste el segundo de los cinco poemas que aparece en el "Arco de la historia y sus pliegues", una de las secciones que

percibir la historia propia, incluida la de la conquista (1997:240). Por lo mismo, según Carrasco, la escritura mapuche-huilliche, en particular, hace frente a los procesos de aculturación y de re-etnización que pesan sobre esta etnia, todo lo cual, desde la conquista — re-editada por la ocupación de la Araucanía — se ha hecho presente mediante la fuerza, la anulación y marginalidad del modo de ser indígena, que se traduce en marginalidad linguística, social, política y educacional (240); conflictividad también presente en poetas chilenos de inclinación etnocultural (Riedemann, Karra Maw'n, 1995; Torres, De Indias, 1993), quienes igualmente re-escriben sobre las marcas de la conquista, en la cultura y en la literatura nacional, asi como sobre la presencialidad de ese pasado al modo de un doble código linguístico y temporal. Cuando en Lienlaf se despierta "el ave que anida en su corazón" (1989), no sólo se ve transportado hacia el arquetipo de Lautaro que "anda de pie/ sobre esta tierra", sino, igualmente, hacia el espacio mítico-histórico de la ciudad (mapuche) de Temuco, debajo de la cual "Están durmiendo/ mis antepasados". En última instancia, la literatura mapuche-huilliche es la emergencia de la necesaria voz que interroga sobre el mundo mapuche, en términos como los de María Isabel Lara Millapán: "Y si se van tus sueños/y olvidan la palabra de los abuelos tus labios / ¿Adónde quedan los hijos de la tierra? / ¿A quién enseñamos el silencio de nuestros bosques?” (2002:60).

${ }^{4}$ Sobre esta noción en la poesía huilliche de Paulo Huirimilla, Hugo Carrasco Muñoz y Selva Mora Seguel han señalado que "la noción de 'palimpsesto', de amplia tradición retórica, fue reformulado parcialmente para su funcionalidad literaria por Gerard Genette (1989) “(...) El palimpsesto, en tanto construcción discursiva, se reconoce como un híbrido pues entrelaza simultáneamente dos tiempos, dos voces, dos contenidos, dos espacios y, por ende, dos culturas que pueden ser muy diferentes. Da cuenta de la tensión entre lo pasado y lo presente, la historia memoria y lo actual, donde 'lo anterior' surge y se devela" (2006). 
componen el poemario (103-106). Los otros poemas de esta sección, son: "El áspero sueño del cronista", "Ese difícil oficio de leer a Encina", "La historia recolecta monedas falsas", y "Arco del retorno".

$\mathrm{El}$ poemario se cierra con "El arco y sus interrogaciones", una réplica del texto que la comunidad del Guillatun pronuncia en la ceremonia religiosa, y que funciona como apertura y cierre de la escritura del poeta y de su lectura sobre la historia de la conquista de su pueblo.

"La historia es historia de la Nación", acota Ricoeur en su re-lectura de Halbwachs (2010:508). Re-pensarla, discutirla o "polemizar" con ella, es alterar el orden canónico del discurso oficial, meterse con el rastrillo de la lectura-escritura en las grietas abiertas de la memoria, o aún posibles de abrir, para cuestionar, poner en duda y enunciar de nuevo, mostrando los reveses de lo que aparece como verdadero e irrefutable. Re-leer la historia mapuche-huilliche requiere descifrar el lenguaje oculto, el lenguaje de un lado interno y externo de un "Arco-libro", que es "puerta" y "ventana" a la vez, aunque ello sea un intento difícil: "Y fue difícil leer el lenguaje / oculto", dice Colipán en el poema "Ese difícil oficio de leer a Encina" (107-108), porque las prácticas sociales han operado por años y con fuerza en la legitimación del discurso canónico de la dominación hispánica, identificado con Encina y con su función historiográfico-docente. ${ }^{5} \mathrm{Y}$, en efecto, si la historia es algo que se enseña (Ricoeur, 2010:508), Colipán nos recuerda que Encina maestros de escuela,
puzzles
y varias calles aún
llevan hoy su nombre.
[...]
La historia es un ojo,
sumergido en la noche,
palabras
para no ser dichas
sino para mirarnos en ellas
como si fueran
un espejo roto (107)

Por años estuvo en la boca de muchos

Por lo mismo, el poema argumenta que la historia del pueblo mapuchehuilliche contada por Encina es un discurso no transparente, que sólo "recolecta monedas falsas", motivo explícito de la sección "Arco de la historia y sus pliegues".

\footnotetext{
${ }^{5}$ Bengoa sostiene que Francisco Antonio Encina justifica la conquista española señalando "que no fue una guerra de españoles contra araucanos, sino de indios afectos capitaneados por españoles, contra indios comandados por sus caciques, y más tarde, por mestizos o cruzados españoles, como Alonso Díaz o el cura Barba" (2000:29).
} 
Según se ha descrito hasta ahora, en Arco de interrogaciones, Bernardo Colipán explicita una escritura de carácter metadiscursivo y exegético que "conforma una estrategia textual dialógica", en la cual participan diferentes prácticas discursivas: notas, citas o párrafos completos de textos científicos, históricos y poéticos estableciendo, así, "una red significativa textual, metatextual e intertextual que dinamiza" (Contreras, 2005:44) una estética particular conforme a la instancia de proferición de un hablante situado etno-culturalmente, según se aprecia en el poema seleccionado para éste análisis.

A nuestro juicio, los formantes textuales y paratextuales de Arco de interrogaciones establecen una estrategia textual dialógica, más bien polémica, que preside todo el poemario. Desde la dedicatoria colectiva (5), el epígrafe (7), el discurso metatextual del autor (9), las notas bibliográficas, etimológicas, autobiográficas $o$, desde los poemas mismos, se observa una voluntad exegética complementaria, que orienta precisas expectativas de lectura. La pluralidad cultural y étnica de las dedicatorias remite hacia ancestros y poetas huilliches y no huilliches. El discurso chamánico selk'nam del epígrafe es una cifra de la memoria, en tanto regreso al pasado - "un caminar al revés", se afirma- para vencer al olvido con el recuerdo y "desplegar el abanico de la memoria", tesis que el autor expresa en "El arco y el despliegue de la memoria" (9), prosa inaugural e interpretativa que actúa como horizonte de lectura de Arco de interrogaciones.

Pero, este "arco" es un dispositivo de discursividad interrogante, inquisitiva, que apunta a dar en un blanco preciso: en la memoria antes que en el olvido; en una historicidad híbrida, no en una a-historicidad enajenante; en la sacralización identitaria, antes que en la desacralización profana (Ricoeur, 2010:509). Este "arco" de Colipán es el umbral donde se formulan interrogaciones que "agujerean al tiempo, lo traspasa para nombrarlo y con ello deshilvanan la madeja del olvido, hacen de la memoria un espacio habitable" (9), dice el poeta. "Es que hay que ir hacia atrás buscando pliegues de la memoria, hay que peinar el tiempo al revés para buscar las trampas de la memoria, para deshacerlas, porque la historia oficial está llena de ellas", nos dijo un día Bernardo Colipán. ${ }^{6}$

Por lo demás, este "arco de interrogaciones" es, también, símbolo verbalizado del espacio sagrado del Guillatun, rito y ceremonial de la sacralidad huillichemapuche, ocasión en que "la palabra traduce/ la reunión de las cosas" (15) dispersas en el mundo huinca. Según exégesis de Colipán, el colihue que hunde sus dos extremos en la tierra, más que como signo visible del lugar de las rogativas, demarca un espacio sagrado, interno, propio del hombre huilliche-mapuche frente a un territorio de la historia, un territorio ajeno (Ricoeur, 2010:510), externo, "huinca". El arco se constituye en un signo de carácter topológico, una puerta o una ventana que demarca el adentro al cual se pertenece, y el afuera de los otros. Se trata de umbrales

\footnotetext{
${ }^{6}$ Conversación personal con el poeta (octubre de 2009), en viaje desde Osorno a Cañete.
} 
limítrofes que Colipán demarca verbalmente, recurriendo a una "invocación" en mapudungun, con la cual inaugura (13) y clausura (113) las interrogaciones que, en la lengua de Castilla, han sido formuladas en cada poema.

Esta "invocación" en la lengua propia actúa, también, como un arco verbal que abraza y ciñe, gesto mediante el cual la lengua nativa atrapa, subvierte y subordina, excepcionalmente, la lengua hegemónica del otro — que habla de otros y hablan los otros - que no actúa como mediadora entre el hombre y los dioses propios, como lo sería el mapudungun. ${ }^{7}$ Por lo mismo, no es preciso recurrir a la estrategia de una doble codificación sin más. La "invocación", en lengua huilliche, remite a la clave identitaria de un ritual cultural y sagrado, cuya sacralidad reside en la lengua misma, que no requiere ser traducida para quienes no pertenecen a esa comunidad cultural, sino que pertenece a quienes mediante la lengua logran —abstrayéndose de sí mismos - el acceso a la puerta o ventana de lo sagrado.

Desde otra perspectiva, los textos -así enmarcados por la invocación en lengua de la tierra - remiten a una actitud contemplativa frente a los cuatro puntos cardinales del cosmos (reeditado en el espacio sacralizado del Guillatun), cuya cardinalidad y transcurso rítmico-ceremonial denuncia el modo como la contraparte huinca, dice o traduce las ceremonias e interrogantes que el mundo mapuche-huilliche se formula en el poemario.

\section{DE CRÓNICAS Y CONTRA-CRÓNICAS}

La superposición e imbricación de códigos verbales se aprecia en el circuito textual-escritural que enmarca, a su vez, al poema "De Chilensibus". Este ciclo comprende:

- Expedición de la Compañía holandesa indo-occidental, bajo el mando de Enrique Brouwer a Chiloé y Valdivia, en los años 1642 y 1643.

- Testimonio oral, hacia 1643, del holandés Brouwer a Giorgius Marcgravius, hablante alemán, sobre un pueblo y una lengua desconocidos como son "los de Chile".

- Versión de ese testimonio en un capítulo de la Historia rerum naturalium Brasiliae, escrita en latín por Marcgravius (Amsterdam, 1648), quien recurre a fuentes adicionales en español, como las de Alonso de Ovalle y su Histórica relación del Reino de Chile, (1648).

- Extracto de la Histórica relación del Reino de Chile, del Padre Alonso Ovalle, acerca de algunos aspectos de la meteorología e historia natural de Chile.

\footnotetext{
${ }^{7}$ Como expresa Mora Curriao, "no sólo hemos tenido que comunicarnos cotidianamente en una lengua Otra, sino que hemos tenido que traducirnos en distintos formatos para darnos a entender" (2009:179); distintos formatos y códigos, discursos y géneros que proceden de la conquista, de la historiografía y de la literatura nacional y europea, de la crónica periodística, de memoriales y de la memoria colectiva y oral, de informantes y ancestros, como en Pulotre (1999) y Ceremonias (2005), de Bernardo Colipán.
} 
En esta secuencia de correlaciones: oralidad-escritura-traducción-lectura, queda de manifiesto la ausencia de la lengua propia, la voz originaria. El mapudungun queda subordinado a las prestigiosas lenguas imperiales del siglo XVII, a su encriptamiento superior en el latín, y a su posterior traducción al "español" como lengua oficial de Chile —y, por extensión, de los pueblos originarios- en el año $1951 .^{8}$

La respuesta a estos silencios y dominancias es la contra-crónica de Colipán que se estructura sobre la figura de la ironía, procedimiento que Perelman y Olbrechts-Tyteca (1989) incluyen como una de las formas de la argumentación. La ironía se emplea para dar a entender lo contrario de lo que efectivamente se dice, mediante una estructura que suma dos discursos. En la ironía se comienza con la asunción provisional de lo que se quiere poner en ridículo y, luego, se agregan conocimientos complementarios respecto de los hechos primeramente formulados, de manera que estos aparecen enunciados desde la ignorancia.

El recurso de la ironía llega — en el texto de Colipán — a su grado máximo mediante la amplificación ecoica del texto de Marcgravius, usando tanto el propio registro del poema, como la voz del cronista. ${ }^{9}$

"De Chilensibus", se enuncia con verbos en plural de tercera persona, mediante los cuales un cronista (Marcgravius), da cuenta de una externalidad observada u observable como ajenidad o extrañeza, la de seres que designa como "ellos", los "otros": los "chilensibus" ("Ellos andan"). A su vez, mediante los pronombres y verbos en primera persona plural ("nosotros" = "yo" y "tú" a quien le hablo y que eres igual a mí), el cronista se representa a sí mismo como integrante de una colectividad de excepción y como un naturalista y observador científico que habla desde una experiencia positivista (vivida) de la cual es testigo: (nosotros) "vemos". Cuentan, también, las citas entrecomilladas que responden, textualmente, a la lectura de Marcgravius, y que el hablante utiliza para llevar a cabo su estrategia ironizadora en el poema ("esto dijeron y aún dicen de nosotros"). Por lo mismo, el saber agregado parece proceder de observaciones del mismo Marcgravius, como frases que quedan en el aire, sonámbulas, sin lograr desentrañar su sentido, junto

\footnotetext{
${ }^{8}$ Carlos Henckel Ch. tradujo el capítulo "De Chilensibus" del texto Historia rerum naturalium Brasiliae. En el párrafo inicial, explica que Marcgravius "se basa principalmente en los datos proporcionados por los marinos que tomaron parte en la expedición de la Compañía holandesa indo-occidental, bajo el mando de Enrique Brouwer a Chiloé y Valdivia en los años 1642 y 1643”.

(en línea: http://www.memoriachilena.cl/archivos2/pdfs/MC0000568.pdf).

${ }^{9}$ Nina Crespo reseña que "Dentro de la tradición retórica y de la pragmática tradicional se afirma que con un enunciado irónico el emisor dice algo opuesto a aquello que quiere comunicar (Seale, 1993). Esta idea ha producido muchas polémicas (Creusere, 1999; Anolli, Infantino \& Ciceri, 2001), pues no siempre el emisor de una ironía oral comunica lo contrario de lo que afirma a un interlocutor presente en un contexto dado... El emisor no necesariamente está comunicando algo contrario a lo que se dice, sino que intenta señalar el poco interés que hay en escucharlo... Tomando en cuenta estas consideraciones, sí es posible destacar la idea de que para la comprensión de una ironía es necesario percibir la determinada actitud del emisor hacia aquello que enuncia y hacia su posible interlocutor, ya sea burla, sarcasmo, indiferencia, etc.” (2007:80ss.).
} 
con las observaciones derivadas de la contralectura que hace el poeta. La ironía radica, entonces, en que el poeta suma otras observaciones - emulando la voz del cronista, o simulando ser su eco- que traduce en un discurso que, pese a contener más información, enfatiza el extrañamiento, revelando con ello su incapacidad para comprender a los otros, esos "chilensibus" ("Vemos con admiración").

La ironía, conforme a Perelman y Olbrechts-Tyteca — cuando hablan del ridículo - surge cuando alguien se opone a la lógica o a la experiencia, o bien, cuando ese otro enuncia principios cuyas consecuencias imprevistas lo enfrentan con concepciones que son obvias en una sociedad dada. Tal obviedad respecto a las concepciones de la sociedad mapuche no es, sin embargo, entendida por el cronista ni tampoco es conocida por el lector del texto de Colipán. De allí que, para mostrar las limitaciones de Marcgravius, el poeta asume la tarea de enunciarlas, entrando y saliendo del tiempo, yendo desde el interior al exterior del espacio sagrado del "Arco de la Interrogación" para que, mediante la memoria y la re-escritura poética, se desplieguen al afuera, donde — según señala Colipán en el prólogo — "se juega su sentido nuestra historicidad" (9). Colipán selecciona fragmentos, fisuras textuales por donde ingresa al discurso del cronista para contraponer la visión mapuche, para dejar en evidencia que el relato del otro sobre su pueblo no es relato verdadero, sino una mirada eurocéntrica, una versión superficial y estigmatizada sobre lo que pretende describir: la vida y las costumbres mapuches en un lugar llamado "Chile". Establecido el proceso intertextual, Colipán ironiza el discurso de Marcgravius, deja en evidencia que es una visión lejana y acentúa la calidad de segunda mano de la cual se sirve Henckel - el traductor-historiador-chilenocuando da cuenta de sus fuentes documentales del capítulo De Chilensibus (119).

Pero, el mecanismo que Colipán pone en juego para lograr la ironía no es la estricta negación de lo que ha escrito Marcgravius, sino la paráfrasis y amplificación de lo dicho por éste. Tal amplificación — construida sobre la base de conocimientos complementarios - trasluce lo que denominamos el discurso de la extrañeza, que se elabora sobre ese otro -el sujeto "chilensibus"- que altera nuestro fondo de comprensión, nuestra solidez cultural, el comportamiento que se espera ver replicado en el otro. Marcgravius describe a los indígenas chilenos con el mismo asombro con que un científico da cuenta de su objeto de estudio, cuando dice: "Vemos con admiración", lo que - en cierto modo - explica el "hallazgo admirable" del texto de Macgravius y, luego, que la traducción de Henckel fuera leída en sesión solemne de la Academia Chilena de Ciencias Naturales, el 29 de abril de 1951. Al igual que la ciencia de la época, el discurso de tono científico del cronista es capaz de describir, pero no genera comprensión, salvo un imaginario "admirabilis".

La cientificidad discursiva se evidencia en las detalladas descripciones morfológicas de Marcgravius: "los indígenas chilenos son generalmente de cuerpo bastante robusto y fornido; de color entre blanco y moreno; de cabellos negros y 
gruesos" (119-120) / "Son casi siempre de cabeza un poco grande y de cara larga, imberbes" (120). En la primera de las tres partes que constituyen el poema De Chilensibus, esta descripción morfológica es uno de los pliegues por donde Colipán ingresa al discurso de Marcgravius:

"Tienen cabezas grandes y anchas".

Luego de parafrasear a Marcgravius evidenciando el origen del enunciado con comillas, Colipán continúa con una amplificación del discurso del cronista que va desde la fisonomía externa hasta el plano de las creencias:

Creen que llueve cuando el estero

suena más fuerte de lo acostumbrado.

Enseñan a sus hijos que la muerte

es el término de un ciclo y que volvemos

nuevamente a vivir en el corazón

de quien desea escucharnos (103).

El verso "Creen que..." nos sitúa en presencia del discurso del cronista, en las creencias, evidenciando con ello el estereotipo de la tradición antropológica según la cual, la cultura propia produce conocimiento y religión, mientras que la cultura del otro produce respectivamente creencia y mito. Pero luego, la amplificación discursiva se enhebra con el verbo "enseñan", lo que implica el reconocimiento de un ser que educa: Enseñan a sus hijos que la muerte (...). Colipán nos hace pensar que es el cronista quien sigue hablando, y en esta amplificación lo exhibe en su incapacidad de reflexionar acerca de este otro que tiene una morfología / Cree en algo / Enseña a sus hijos (...). Es el momento de la fisura, donde el poeta proyecta el sentido de lo trascendente del mundo mapuche - gracias al carácter sagrado del topos "espaciotiempo", del Arco de Interrogación - permitiendo que se distiendan los pliegues de la memoria, de modo que ésta se vuelve un topos habitable. Desde esta singular instancia de enunciación, el poeta procede a un cruce de temporalidades: entra y sale de su tiempo; desde su hoy al ayer y desde ese ayer hasta su presente, en un contrapunto entre un "nosotros" y el "ellos", mediante el cual emerge el admapu, la enseñanza tradicional, de lo trascendente: y con ello la construcción de una cultura compleja que el otro (ahora el "otro" es el dominante) no es capaz de conocer.

(Ellos) Dicen que en esta vida somos sólo pasajeros

(Nosotros) decimos que en esta vida [no] somos sólo pasajeros... ¿?, o

(Pero, "nosotros", también) decimos que en esta vida somos sólo pasajeros...i!

De esta forma, el poema postula una contra-argumentación irónica que pone en evidencia la incompletud del escrito del cronista y deja una interrogante al pragmatismo cotidiano de la modernidad que objeta en los "chilensibus". Ellos

"Siembran o plantan lo que necesitan

para el año siguiente".

No capitalizan.

No entienden la propiedad privada. (103) 
No tienen riquezas.

"Viven sin ningún cuidado" (104)

El contrapunto "entrada y salida del tiempo" se juega ahora en el lenguaje: mientras las citas de Marcgravius aparecen entre comillas - "Viven sin preocupación alguna, no siembran ni plantan más que cuanto necesitan para el próximo año" (122), dice la traducción del texto en latín de Marcgravius - los vocablos capitalizar y propiedad privada remiten al "hoy" y al lenguaje actual del sistema capitalista libremercadista. El asombro, ahora, es por otra razón. No capitalizan / no entienden la propiedad privada / No tienen riquezas, son enunciados que no se amplifican mediante nuevos conocimientos (todos ellos enuncian lo mismo: la no acumulación de riquezas), sino que aparecen como si formaran parte de una misma sincronía, para enfatizar que la misma mirada sesgada del pasado tiene plena vigencia hoy como saber asignado y heredado.

Luego, la amplificación proviene del enunciado sobre la trascendencia. Por momentos, Marcgravius parece percibir extrañado, sorprendido, una hipotética afinidad entre el "nosotros" y el "ellos" (dicen que en esta vida somos sólo pasajeros); parece estar cerca de advertir que hay un sentido oculto en la elaboración ideológica de la sociedad mapuche, pero esta suerte de murmullo que replica en su mente, no le es suficiente para que tome conciencia de que quien en realidad no entiende es él, el cronista en su calidad de "testigo de oídas", quien, en la segunda sección del poema, concede que

Sin embargo, cierto conocimiento de un Ser / Superior parecen tener (105).

Estas afirmaciones — dadas como cualidades o virtudes posibles de ser encontradas en los "chilensibus" - amplifican las observaciones del cronista no presencial quien, por momentos, parece acercarse a la comprensión de su objeto mediante un nexo, como es la sobreposición de una semejanza posible

"Nosotros también

cierto conocimiento de un Ser

Superior tenemos"

Tanto como de una (in)cierta noción metafísica, según se admite a continuación en el poema

Creen que lo visto en sueños

es posible que suceda

y que ni dueños somos

de la bella nada que nos une (105).

En este momento, ante la concepción poética y religiosa del universo que refiere la crónica-poetizada, Marcgravius abre la posibilidad de entrever al otro en 
sus afanes de trascendencia. Sin embargo, es sólo un momento de imprevista digresión, pues, rápidamente, se impone el discurso etnocéntrico del cronista

Todo lo abandonan por sentir nuevamente en sus rostros el polvo de los nguillatunes. Tienen por superstición creer que los límites del alma no se encuentran (105).

$\mathrm{Al}$ final de esta segunda secuencia, el poeta huilliche-chilensibus reelabora lo enunciado por Marcgravius. Mientras el cronista escribió que "gozan del humo del tabaco" (126) y que pronuncian sermones "lo que los nuestros (los holandeses de Brower, tan europeos como él) no pudieron comprender de manera alguna" (126), por cuanto su lengua es otra, Colipán escribe

Fuman tabaco en ciertas ceremonias

junto a otras cosas

que no quieren

que comprendamos (105).

Estos versos implícitamente llevan a preguntarnos ¿Quién es el que no quiere o no puede comprender? ¿Aquel que no habla la lengua de los "chilensibus", ni reconoce en ellos su paridad, su calidad de ser como los "nuestros" (vale decir "yo=ellos")?

La tercera parte del poema que aquí analizamos incluye enunciados recogidos y/o reelaborados como discurso de Marcgravius, los que son presentados en modalidad negativa. La negación se establece sobre una afirmación previa de la cual es su reverso: el enunciado afirmativo es la construcción del mundo del cronista, quien al no verse reflejado en los "chilensibus" desarrolla la negación ontológica del indígena

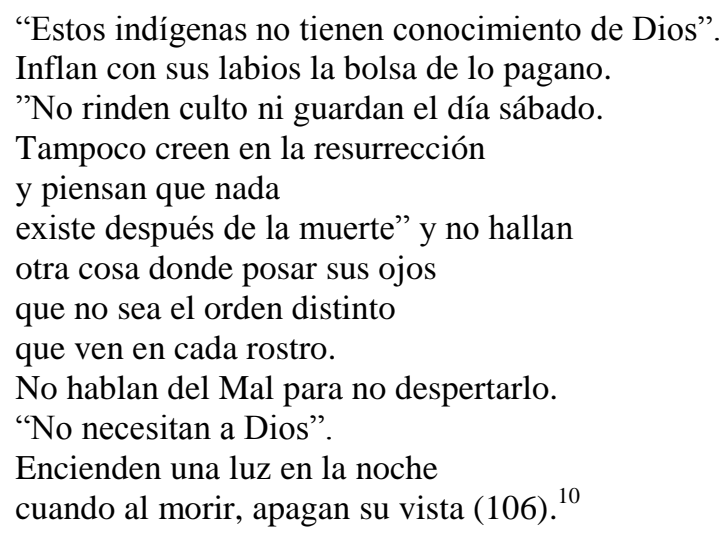

\footnotetext{
${ }^{10}$ Marcgravius dice "Los indígenas chilenos ni conocen a Dios, ni su culto, no observan ninguna diferencia entre los días, ni creen por lo menos en la resurrección de los muertos, sino estiman que después de la muerte nada del hombre subsiste" (125).
} 
La amplificación va aquí, también, por la vía de la doble negación que permite la percepción de un "orden distinto", extraño, que el cronista no puede dilucidar, por cuanto es signo de una otredad, de una oposición con respecto al mundo propio del europeo: No son judíos, por cuanto "no rinden culto ni guardan el día sábado". Sin embargo, "al morir apagan su vista... encienden una luz en la noche misma del morir", como apertura a una trascendencia, a una claridad que no le consta al cronista.

En consecuencia, lo que el poema afirma es su capacidad e interés para hablar desde la mismidad del sujeto "chilensibus", poner a la vista y ver lo diferente, aquello que el cronista no ha podido lograr.

En suma, "De Chilensibus" presenta precisos lugares estratégicos, que establecen un particular campo semiótico compuesto por "una red significativa textual, metatextual e intertextual, que dinamizará y particularizará su modalidad escritural' (Contreras, 2005:44). Como fue analizado, el título del poema reproduce, fragmentariamente, el título de un apartado de la Historia rerum naturalis Brasiliae, compuesto por seis capítulos, en los cuales Marcgravius - durante sus estudios etnográficos sobre el Brasil- extiende su relación hacia los "nativos del sur de Chile" (Chiloé-Valdivia), conforme a la relación de Brouwer. La nota al pie del poema, advierte que estamos en presencia de un acto de lectura de Marcgravius; una lectura respecto a lo que este científico ha escrito acerca de una etnia de Nuevo Mundo, de la cual el hablante lírico forma parte hoy; pero lectura, también, en la cual este hablante no se reconoce como uno de aquellos sujetos que Marcgravius describe y califica, y de quien, extrañado, transcribe expresiones antropológicas textuales relativas al físico, vestuario, vivienda, comidas, religión, economía, trato con la naturaleza y con la vida. Por esta vía, el poema instala un "ir hacia atrás buscando pliegues de la memoria", pone "el tiempo al revés para buscar las trampas de la memoria, para deshacerlas, porque la historia oficial está llena de ellas", según el programa poético de Bernardo Colipán.

A partir de aquí, en el poema-lectura se establecen una serie de exclusiones recíprocas del hablante-lector, como reacción respecto a la escritura anómala de Marcgravius, quien — en los nativos chilenos que le han descrito - no reconoce sino los signos de su propia identidad cultural eurocéntrica. ${ }^{11}$ Marcgravius opone lo otro

\footnotetext{
${ }^{11}$ En el fondo, lo que se plantea es la "extrañeza" frente al "otro" sujeto que pertenece a "otra" cultura, sea ella entendida como un todo complejo que incluye conocimiento, creencias, arte, moral, leyes, usos y otras capacidades y hábitos adquiridos por el hombre como miembro de una sociedad (Taylor); como conducta aprendida en una sociedad o en un subgrupo (Mead); como modos específicos de organizar la producción, la estructura de la familia y de las instituciones que expresan gobierno o relaciones sociales; como formas características a través de las cuales los miembros de la sociedad se comunican (Willliams); o como un "conjunto de relatos que habla de nosotros y sobre nosotros" (Geerts). Cfr. SARDAR, Ziauddin; Van Loon, Borin. Introducing cultural Studies. Singapur: Tien Wah Press, 2003, a quienes glosamos respecto a estas definiciones.
} 
como ajeno, eso que - por su parte- el hablante lírico-mapuche-chileno reconoce como propio a partir de diadas oposicionales como las siguientes

\begin{tabular}{ll}
\multicolumn{1}{c}{ Mapuches } & \multicolumn{1}{c}{ Es } \\
Hombres descalzos & Hombres calzados \\
Hombres de cabezas grandes y anchas & Hombres de cabezas y trazas armónicas \\
Hombres animistas & Hombres no animistas (racionalistas) \\
Sin preceptos de la economía ni del progreso & Con preceptos de la economía capitalista: \\
& incremento del patrimonio \\
Propiedad comunitaria, colectiva & Propiedad privada, individual \\
"No necesitan a Dios" & "Necesitamos de Dios"
\end{tabular}

La extrañeza que preside esta descripción antinómica del yo frente al otro radica en que a Marcgravius le interesa el otro ("el indígena chileno, o de Chile") como especie natural, como un formante más de la flora y la fauna del "reino natural" de Nuevo Mundo, al modo como esas especies que describe del Brasil o de Guinea. Como buen naturalista, las acompaña de las ilustraciones correspondientes, mediante dibujos hechos sólo a partir de la descripción de Brouwer (120). Cataloga y califica a la nueva "especie" que debe integrar a la cultura europea, recurriendo a un latinismo ("De Chilensibus"), cultismo equívoco que designa como "chilenos" a los nativos (sin indagar en su pertinencia o filiación étnica), y no a los descendientes de los conquistadores españoles. La lengua de Marcgravius configura para la comunidad científica del Viejo Mundo una noción de los indígenas de Chile, dada en estos términos; se apodera de esta "especie" de hombres diferentes, en todo sentido — según él-a los semejantes, al sí mismo, al prójimo consabido identificable como tal en la mirada eurocéntrica, plegada sobre sí misma. ${ }^{12}$

El bien escogido recurso de la ironía en "De Chilensibus" supone desmontar, deslegitimar el discurso del "sabio" cronista occidental. La ironía instala la ignorancia en quien ha hablado primero: el ridículo es posible porque quien habla -el cronista - no es consciente de su propia ignorancia. Colipán reversa así la relación dominante - sabio / subordinado - ignorante en dominante -ignorante / subordinado-sabio.

\footnotetext{
12 Todorov explicita que la cuestión del otro supone entrar en contacto con "un grupo social concreto al que no pertenecemos", de manera que la otredad concieme a "todo lo que no es uno mismo" (1987:13). A partir de tales premisas, Todorov describe tres tipologías, que comprenden las relaciones posibles de establecer con respecto a ese otro. Plano axiológico, en tanto juicio de valor: el otro es bueno o malo, lo quiero o no lo quiero, o bien como se prefiere decir, es mí igual o es inferior a mí (ya que, por lo general, y eso es obvio, yo soy bueno, y me estimo). Plano praxeológico, que implica un acercamiento o alejamiento del otro: adopto los valores del otro, me identifico con él; o asimilo al otro en mí; le impongo mi propia imagen; pero entre la sumisión al otro y la sumisión del otro hay un tercer punto, que es la neutralidad, indiferencia. Plano epistémico: conozco o ignoro la identidad del otro, evidentemente — dice Todorov— no hay aquí ningún absoluto, sino una gradación entre los estados de conocimiento menos o más elevado. No ama, no conoce, no se identifica (195).
} 
El poema da cuenta de esta polaridad o reversión de lo conocido en lo desconocido, a partir de los ejes "nosotros" vs "ellos", cuyo axioma es "nosotros no somos ellos, o como ellos, pues, esos "ellos son otros" "13

\author{
Ellos \\ Andan descalzos \\ Son animistas \\ (Creen en hechos sobrenaturales) \\ Ignoran (la cultura) \\ No capitalizan \\ No entienden de propiedad \\ Creen en la vida como transitoriedad \\ No tienen riquezas \\ Viven sin ningún cuidado
}

\section{A}

"Nosotros los europeos vemos con admiración a esta "especie" de hombres ("chilensibus"), a quienes excluimos como pares nuestros, por cuanto no encuentro en "ellos" nada semejante a nosotros.

\author{
Nosotros \\ andamos calzados \\ Somos racionales \\ Sabemos (de la cultura) \\ Capitalizamos \\ Sabemos el valor de la propiedad \\ No creemos en la vida como transitoriedad \\ Acumulamos riquezas \\ Vivimos con cuidado (o temerosos de Dios \\ y de la muerte)
}

ERGO:

Vs

B

Yo - el lector de Marcgravius, el poeta "chilensibus" - me admiro hoy de la descripción excluyente que se hace de nosotros en esa "crónica natural", pues -entre otros atributos- "Estos indígenas sí (no) tienen (tenemos) conocimiento de Dios".

Universidad de Los Lagos*

Departamento de Humanidades y Arte

Avda. Alcalde Fuchslocher 1305. Osorno (Chile)

palvarez@ulagos.cl

ebarraza@ulagos.cl

\section{BIBLIOGRAFÍA}

Bengoa, José. Historia del pueblo mapuche. Siglo XIX y XX. Santiago: LOM, 2000.

Carrasco Muñoz, Hugo; Mora Seguel, Selva. "Lectura palimpséstica de Palimpsesto de Juan Paulo Huirimilla", en Estudios. Filológicos [online]. 2006, n.41 [citado 2011-06-2], pp. 43-54. Disponible en:

<http://www.scielo.cl/scielo.php?script=sci_arttext\&pid=S0071-

17132006000100004\&lng=es\&nrm=iso>.

ISSN 0071-1713., doi: 10.4067/S0071-17132006000100004.

Carrasco, Iván. "La poesía etnocultural en el contexto de la globalización”, en Revista de Crítica Literaria Latinoamericana. Año XXIX. 58:175-192.

${ }^{13}$ Desde la perspectiva colonial, el otro es simplemente un "bárbaro", aquel que — según describe Bartolomé de Las Casas - provoca una "extrañez y exorbitancia ó novedad que discorda la naturaleza y razón común de los hombres” (1909:686). 
Casas, Bartolomé de las. Apologética Historia de las Indias. I. Madrid: Bailly-Baillière é Hijos. 1909. Nueva Biblioteca de Autores Españoles N¹3. Edición de D. Serrano y Sanz.

Césaire, Aimé. "Discurso sobre el Colonialismo" (1955), en Fuentes de la cultura latinoamericana. Leopoldo Zea (compilador). México: F.C.E., (III vols.), Volumen II. 1993.

Colipán, Bernardo. Arco de interrogaciones. Santiago de Chile: LOM, 2005.

Contreras, Verónica. "Los méritos poéticos de la actual generación: La textualidad poética en la escritura de Bernardo Colipán", en García Barrera, Mabel; Carrasco Muñoz, Hugo y Contreras Hauser, Verónica. Crítica situada. El estado actual del arte y la poesía mapuche. Temuco: Florencia, 2005:37-46.

Crespo, Nina; Ricardo Benítez; Pablo Cáceres. "La comprensión de las ironías orales", en Estudios Filológicos, N 42 (2007):79-94.

Encina, Francisco. Historia de Chile. Desde la Prehistoria a 1891. Santiago de Chile: Nacimento, 1940-1952:20v.

Foerster G., Rolf. "La poética mapuche huilliche como procedimiento de la rememorización", en Mabel García et al. Crítica situada. El estado actual del arte y la poesía mapuche. Temuco: Universidad de la Frontera, 2005:273-285.

García Barrera, Mabel; Carrasco Muñoz, Hugo; Contreras Hauser, Verónica. Crítica situada. El estado actual del arte y la poesía mapuche. Temuco: Florencia, 2005:285.

García, Mabel. "Lenguaje, traducción y resistencia cultural en el discurso poético mapuche: Arco de interrogaciones de Bernardo Colipán”. I Congreso Latinoamericano de Antropología. Rosario: Universidad Nacional de Rosario, 2005.

Huenún, Jaime. Puerto Trakl. Santiago de Chile: LOM, 2001.

Huinao, Graciela. Walinto. Santiago: La Garza Morena, 2001.

Huirimilla, Juan Paulo. Palimpsesto. Santiago de Chile: LOM, 2005.

Lara Millapán, María Isabel. Puliwen Ñi Pewma - Sueños de un Amanecer. Villarrica: PUC, 2002.

Marcgravi De Liebstad, Georgi. "De Chilensibus", en Historia rerum naturalum Brasilae. Libri octo. Lungduni Batavorum et Amstelodami, 1648. Henckel, Carlos. "Georgius Marcgravius - De Chilensibus", traducción leída en la sesión del 29 de abril de 1951 de la Academia Chilena de Ciencias Naturales (http://www.memoriachilena.cl/archivos2/pdfs/MC0000568.pdf).

Mora Curriao, Maribel; Huinao; Millapán; Manquepillán; Panchillo; Pinda; Rupailaf. Hilando en la memoria. Epu Rupa. Santiago de Chile: Cuarto Propio, 2006.

Nagy Zekmi, Sylvia. “¡Vienen los hincas a guerrear! El testimonio femenino mapuche como género de resistencia", en Lengua y Literatura mapuche. № 7 . Temuco: Universidad de la Frontera (1996):59-71.

Perelman, Chaïm; Olbrechts Tyteca, Lucie. Tratado de la argumentación. La nueva retórica. Madrid: Gredos, 1089. (1 $1^{\mathrm{a}}$ ed. 1958).

Ricoeur, Paul. La memoria, la historia, el olvido. México: F.C.E., 2010.

Riedemann, Clemente. Karra maw’n. Valdivia: El Kultrún, 1995.

Said, Edward. Cultura e Imperialismo. Barcelona. Anagrama, 2001.

Sardar, Ziauddin; Van Loon, Borin. Introducing cultural Studies. Singapur: Tien Wah Press, 2003.

Todorov, Tzvetan. La conquista de América. La cuestión del otro. México: Siglo XXI, 1987. Torres, Nelson. De Indias. Santiago de Chile: San Cristóbal, 1993. 